ACTHOR'S ABSTRACT OF THIS PAPER ISSUED BY THE BIBLIOGRAPHIC SERVICE, MARCH 14

\title{
THE FATE OF THE NEURAL CREST IN THE HEAD OF THE URODELES
}

\author{
F. L. LANDACRE
}

Department of Anatomy, Ohio State University

ELEVEN FIGURES

CONTENTS

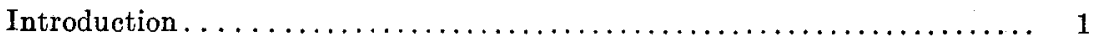

Historical sketch $\ldots \ldots \ldots \ldots \ldots \ldots \ldots \ldots \ldots \ldots \ldots \ldots \ldots \ldots \ldots \ldots \ldots \ldots \ldots \ldots \ldots \ldots \ldots \ldots . \ldots \ldots$

Material $\ldots \ldots \ldots \ldots \ldots \ldots \ldots \ldots \ldots \ldots \ldots \ldots \ldots \ldots \ldots \ldots \ldots \ldots \ldots \ldots \ldots \ldots \ldots \ldots \ldots \ldots . \ldots$

The origin of the neural crest $\ldots \ldots \ldots \ldots \ldots \ldots \ldots \ldots \ldots \ldots \ldots \ldots \ldots \ldots \ldots \ldots 11$

The migration of the neural crest and its relation to the mesoderm . . . ... 13

The derivatives of the lateral ectoderm $\ldots \ldots \ldots \ldots \ldots \ldots \ldots \ldots \ldots \ldots \ldots$

The oral ectoderm $\ldots \ldots \ldots \ldots \ldots \ldots \ldots \ldots \ldots \ldots \ldots \ldots \ldots \ldots \ldots \ldots \ldots \ldots$

The differentiation of the mesoderm and neural erest in the head....... 28

Summary . . . . . . . . . . . . . . . . . . . . . . . . . . . . 32

Literature cited $\ldots \ldots \ldots \ldots \ldots \ldots \ldots \ldots \ldots \ldots \ldots \ldots \ldots \ldots \ldots \ldots$

\section{INTRODUCTION}

During the course of an investigation of the origin of the cerebral ganglia of the urodeles it became necessary to determine accurately the ventral limits to which the neural crest migrates. In the attempt to do this the distribution of the neural crest was found to be so extensive and to involve so much tissue of a non-nervous character that it was decided for the time being to discontinue the study of the cerebral ganglia and follow the history of that portion of the crest which is not concerned in the formation of these ganglia.

The ventral limit of ganglia into the composition of which the neural crest enters, namely, V, VII, IX, and X, is at the level of the epibranchial placodes, approximately at the dorsal border of the corresponding gill slit. The neural crest in all vertebrate types, apparently, migrates ventral to this level beyond its ganglion-forming region and further is distributed in the head of the embryo anterior to the level of the gasserian ganglion. 
Only a relatively small portion of the neural crest in the head is involved in the formation of cerebral ganglia.

In the urodeles the neural crest forms in the anterior head region an almost continuous sheet of mesenchyme, lying lateral to the axial mesoderm which is derived from the endoderm, and is interrupted for a time by the olfactory bulb and optic stalks only. In the region of the mandibular and branchial bars, the neural crest migrates ventrally into these bars to the extreme ventral level of the body and is prevented from forming a junction with the crest of the opposite side bv the presence of the heart and ventral aorta.

The possibility of determining the fate of neural crest cells that do not enter into the composition of cerebral ganglia depends upon conditions that exist in some types and are apparently absent in others. It is the almost unanimous opinion of workers that it is extremely difficult and often impossible to determine the fate of all neural crest cells in the anterior head region. In the branchial region of the lower vertebrates particularly, the situation is very different. A number of reliable workers have given detailed descriptions of the fate of the neural crest cells and of the manner in which they enter into the composition of structures usually considered as mesodermal in origin. As to the migration of the neural crest beyond ganglion-forming regions in all vertebrates, there is apparently little doubt.

In the urodeles the determination of the extent of the migration of the neural crest and the differentiation of the neural crest and its derivatives from those of the endoderm are comparatively easy except in the anterior region. The contrast between the large, heavily yolk-laden, light staining endoderm cells and their derivatives on one hand and the smaller, dark staining, pigmented, slightly yolk-laden ectoderm cells and their derivatives on the other hand is very striking. In addition to these distinctions based upon size of cells, staining reaction, pigmentation, and number of granules, there is also an actual difference in the size of yolk granules carried by endoderm cells as compared with those carried by ectoderm cells, those carried by endoderm cells being larger. These distinctions, furthermore, 
persist up to so late a stage in development in certain regions of the head that it can be determined accurately that head structures, usually considered as of mesodermal origin, are derived from the ectoderm of the neural crest.

\section{HISTORICAL SKETCH}

The idea that ectodermal cells, derived from either neural crest or from the lateral ectoderm, can be traced into permanent head structures, other than ganglia, was first stated definitely by Miss Platt in 1893. It was claimed in a preliminary paper published by her at that time that branchial cartilages arose from ectodermal cells. Before the appearance of her paper, however, several papers appeared bearing more or less directly on the fate of the non-nervous portion of the neural crest. Marshall ('78), working on the chick, and van Wijhe ('82), on the selachians, both called attention to the fact that the neural crest is present in the head anterior to the trigeminus ganglion, but could not determine the fate of that portion of the crest which does not enter into the formation of that ganglion.

Kastschenko ('88) went a step farther and stated that, in the head of the selachian embryo, other layers than the endoderm, particularly the ectoblast, take part in the formation of mesenchyme, and that in the formation of the neural crest some of the cells detach themselves from the neural-crest mass, become loosely arranged, and form mesenchyme, while other cells from the same source are concerned in the formation of ganglia. The further fate of the mesenchymal cells is not discussed, neither is their relation to mesenchyme derived from endoderm treated.

Goronowitsch ('92) published a preliminary paper in which he determined for birds not only that the neural-crest cells give rise to mesenchyme in the head region, but that they fuse with the axial mesoderm derived from the endoderm to form a homogeneous mesenchyme in which neural-crest cells can no longer be distinguished. $\mathrm{He}$ also noted a proliferation of mesoderm (mesenchyme?) cells from the ectoderm in the dorsal portion of the gill. 
Miss Platt ('93), as noted above, published a preliminary notice in which she traced the branchial cartilages definitely to the ectoderm derived apparently from the lateral body wall rather than from the neural crest. Her statement is rather hard to follow and caused her work to be criticised and possibly to be misunderstood. She seems to derive the mesoderm from two longitudinal ridges which later break up into three vertical ridges. The median portion of each vertical ridge proliferates mesoderm into the gill arch to form the cartilage of the gill arch. Ventral to this point the lateral ectoderm proliferates cells into the branchial arch to form mesoderm. Miss Platt states that the neural cells (neural crest?) break up into stellate mesoderm, whose fate she is unable to follow. She does not in her preliminary paper introduce the terms 'mesectoderm' and 'mesentoderm' for mesenchyme derived, respectively, from ectoderm and entoderm.

Later in the same year Goronowitsch ('93 a and b) published on the development of the neural crest in birds and fishes and asserted again the origin of mesenchyme from both the neural crest and the lateral ectoderm. He makes the surprising statement that the neural crest is concerned neither in the formation of ganglia nor nerves, but only in the formation of mesenchyme, a part of which latter forms the sheath of Schwann and determines the course of growing nerves. The nerves arise from neuroblasts. Goronowitsch derives mesenchyme from the ectoderm in the region of the gill arch. The periaxial mesoderm comes from both neural crest and from the lateral ectoderm and is associated with the formation of the gill arch presumably, but he does not derive the cartilages specifically from the ectoderm as Miss.Platt had done.

In 1894 Miss Platt elaborated the idea contained in her preliminary paper introducing the terms mesectoderm and mesentoderm for mesenchyme derived from the ectoderm and endoderm, respectively. She further recognizes the neural crest as contributing to the formation of mesectoderm, though the lateral ectoderm is its chief source. The axial mesoderm is recognized in this paper as coming from the endoderm, but in later papers 
(Platt, '96, '97) this is questioned, and as a consequence she discards the term mesentoderm. In these later papers she derives ganglia, nerves, mesenchyme, and branchial cartilages and the dentine of the teeth from the mesectoderm, but neither muscles nor embryonic nerve supporting tissue (sheath of Schwann). In Miss Platt's second paper ('94) she follows the ectoderm cells into the gill bars, but not to their complete differentiation into cartilage. The later history of these cells and their differentiation into cartilages was given in the paper published in 1897.

Later papers by Kupffer ('95), by Lundborg ('99), by Dohrn ('02), and by Brauer ('04) support in the main Miss Platt's contention. However, Rabl ('94), Corning ('99), Minot ('01), and Buchs ('02) do not agree with her interpretation. The criticisms of Miss Platt's theory will be given first.

Rabl ('94) at the Strassburg meeting of the Anatomische Gesellschaft criticised Goronowitsch's description of the mode of derivation of the mesenchyme from ectoderm in birds and teleosts as an assumption; because Goronowitsch admitted that after ectoderm cells fuse with mesoderm he could no longer follow them, and consequently he had no right to assume that they became a permanent part of the mesenchyme. This objection seems to.be valid so far as birds and bony fishes are concerned. His objection to Miss Platt's mode of derivation of cartilage is based not on a study of Necturus, which he admits he has not examined, but on a study of Triton, salamander, and axolotl. He thinks that the appearance, which Miss Platt finds in her preparations, of cells being proliferated from the ectoderm, can be explained best as due to faulty fixation. Rabl makes a vigorous defense of the idea of the integrity of the germ layers. Most of his criticism is devoted to Klaatch's ('94) conception of the origin of the skeleton of the fins of the fishes. Harrison ('95) has since shown that Klaatch was wrong in his interpretation.

Corning ('99) derives, in the Anura, from the neural crest, only ganglia and nerves, the ventral portions of which extend well down into the corresponding branchial arches. The neural crest is closely fused with the lateral ectoderm, deriving some of 
its cells from that source, but in Rana it does not break down into mesenchyme, according to this author. The mesenchyme of the head is derived from the endoderm, and is consequently mesentoderm in Miss Platt's sense of this word or mesoderm in the older sense.

Minot ('01), in an address before the New York Pathological Society, makes a vigorous defense of the doctrine of the integrity of the germ layers, in which he agrees with Rabl ('94), whose opinion was expressed under somewhat similar circumstances. He calls attention to Miss Platt's work specifically and says, "an examination of a number of series and stages has not enabled me to find the slightest evidence in favor of Miss Platt's conclusions." He says further that "we may, therefore, I think safely regard this attempt to overthrow the morphological value of the germ layers as unsuccessful. I know of no other attempt of sufficient importance to be even mentioned." He states in an earlier paragraph that "the efforts to upset the validity of this fundamental doctrine have failed to find support or recognition from any leading embryologist." These statements of Doctor Minot's were made previous to the appearance of the work by (Dohrn ('02) and Brauer ('04), but-after the appearance of that of Kupffer ('95) which he must have overlooked. Both Minot and Rabl seem, in the opinion of the writer, to have given too much weight to the doctrine of the integrity of the germ layers in their estimate of a question; which is purely one of accuracy of observation and description.

Buchs ('02), after studying Necturus, disagrees with Miss Platt's conclusions, taking exception particularly to her statements concerning the derivation of mesenchyme from the lateral ectoderm and to her distinction between mesectoderm and mesentoderm on the basis of the amount and size of the yolk granules. Buchs' opposition to Miss Platt's interpretation of the mesenchyme is based frequently on minor details and possible ambiguities in statements, although he has worked over the same type. He derives cartilage from mesenchyme which arises from endoderm by a folding process of the endoderm and not from ectoderm. He can find no evidence for the wandering of 
the precartilage cells from the nerve anlagen or from the ectoderm. He denies the contribution of cells from the ectoderm to the mesenchyme, but does not follow the fate of neural-crest cells.

Of the writers opposing Miss Platt's hypothesis, two only, Corning ('99) and Buchs ('02), give sufficiently detailed descriptions and figures to enable one to estimate the value of their criticism. Corning certainly did not follow his stages far enough o determine that the mesoderm of the branchial bars is completely surrounded by neural-crest cells. This can be seen on any good series of the frog, Rana pipiens. Buchs, on the other hand, contents himself with an effort at destructive criticism. His actual evidence is of a negative character, since he does not follow the fate of neural-crest cells that do not form ganglia.

Of the authors who support wholly or in part Miss Platt's contention, the earliest is Kupffer. Kupffer ('95) described in detail and figured the cartilages in Ammocoetes as arising from the deeper layer of the ectoderm in the region of the branchial bars. He had previously ('94) designated this layer as neurodermis, believing it to be concerned in the formation of the branchial nerves, but here designates it as branchiodermis and derives not only the cartilages, but goes a step farther than Miss Platt and derives muscles also from it. He agrees fully with Miss Platt's interpretation after examining her preparations. $\mathrm{He}$ further derives mesenchyme in the dorsal anterior head regions from the neural crest.

Lundborg ('99) derived the pterygopalatine cartilages in Salmo salar and the trabeculae in Rana temporaria from the ectoderm of the roof of the mouth. He also derived the ethmoid cartilages in Salmo in the same manner. The anterior end of these cartilages in Salmo are in process of formation in sixtyeight-day-old embryos.

Koltzoff ('02), in Petromyzon, derives mesenchyme in the head from both the neural crest and lateral ectoderm, but is unable to follow its fate beyond the point of the mingling of ectodermal cells with those derived from endoderm. 
Dohrn ('02) gives a full description with numerous figures of the migration of the neural crest ventrally into the branchial region and its metamorphosis into mesenchyme and cartilage of the branchial bars in Torpedo ocillata. He agrees fully with Miss Platt's interpretation of the origin of branchial cartilages from ectoderm, although he derives them from the neural crest rather than from the lateral ectoderm. He does not exclude the contribution of the cells from the lateral ectoderm in later stages, although neither his figures nor text include such a contribution. He adopts Miss Platt's term mesectoderm and criticises the effort of Corning to maintain the integrity of the germ layers in the formation particularly of structures derived from the mesoderm. Dohrn's evidence for the derivation of connective tissues and cartilage from ectoderm is more convincing, if possible, than that of Brauer in the Gymnophiona and of Kupffer in Petromyzon, both of whom give detailed descriptions. Dohrn's figures taken with Neal's ('98) reconstructions of Squalus (figs. 7 to 21, pls. 3 and 4) furnish convincing evidence for the continuous migration ventrally (Neal) of the neural crest and its ultimate transformation into permanent mesenchyme and cartilage of the branchial bars (Dohrn).

Brauer ('04), working on the Gymnophiona, derives mesenchyme of the anterior region of the head from neural-crest cells which later mingle with cells derived from endoderm to form mesenchyme in which the two derivatives cannot be recognized after this fusion. He can find no evidence for the disappearance of these neural-crest cells, however, before their fusion with cells derived from the endoderm. In the posterior head region neural-crest cells, when not involved in the formation of ganglia, grow ventrally into the branchial bars and surround the mesoderm of the bar at first lying on its lateral surface, but finally entirely surrounding it. He can find no evidence for the derivation of mesenchyme in the gill bar from the adjacent lateral ectoderm, as Miss Platt had done, but derives it entirely from the neural crest. He does not deny the possible later mingling of cells derived from mesoderm with those derived from the neural crest, but insists that the chief part in the formation of 
the gill bar is performed by cells derived from the neural crest. Brauer objects to Miss Platt's terms mesectoderm and mesentoderm which had been accepted by Dohrn and Koltzoff. $\mathrm{He}$ reserves his description of the ultimate fate of the ectodermal mesenchyme of the gill bar for a later paper and consequently does not describe the origin of definite cartilage.

An impartial examination of the papers cited above furnishes strong evidence for the formation of the mesenchyme in the anterior head region in the embryo from both endodermal (mesentoderm) and ectodermal (mesectoderm) sources. In all cases the fate of these individual cells is lost and it is not possible to determine the extent to which either or both of them is concerned in the formation of adult mesenchyme in this region. However, evidence for the disappearance of mesectoderm cells in the anterior head region is conspicuously absent. The same statement holds in the main for the dorsal mesenchyme in thr posterior portion of the head.

The fate of the ectodermal derivatives in the branchial regions is much more definitely stated. Platt ('93), Kupffer ('95), Brauer ('04), and Dohrn ('02), all derive either the cartilages and mesenchyme or both cartilages and muscles in addition to mesenchyme from the ectoderm. Platt ('93), Kupffer ('95), and Koltzoff ('02) derive the ectodermal cells in the branchial region largely or even altogether from the lateral ectoderm, while Brauer ('04), Corning ('99), and Buchs ('12) can find no evidence for the proliferation of cells from the ectoderm, and Brauer ('04) and Dohrn ('02) derive the structures in the branchial bar entirely so far as they are ectodermic from the neural crest.

\section{MATERIAL}

The material on which the work was done consists of three series of urodele embryos collected in the same pond, but representing at least two different species. The youngest series (series I) consists of thirty-five stages taken from two egg clusters at intervals of five to five and one-half hours, reared at room temperature, and covers an interval of eight days. The first 
stage of this series was fixed immediately after collection and the medullary folds appear in stage 6 . This series, judged by the size of the egg clusters and character of development, is evidently Plethodon glutinosus.

The second series is older and consists of thirty-two stages taken from four egg clusters reared at room temperature and fixed at intervals of about five hours. The total period covered by this series is about eight days. The youngest stage of this series corresponds closely to no. 32 of series I. The larvae were reared and identified as Plethodon glutinosus. These larvae hatched in the twenty-fourth stage, so that combining series I and II there are fifty-six stages taken previous to hatching.

The third series (series III) consists of fifty-one stages taken from five egg clusters reared at room temperature and fixed at four-hour intervals. The total period covered is again about eight days. The first stage of series III corresponds closely to no. 10 of series I and the twenty-third stage of series III corresponds to no. 1 of series II. The larvae of this series were reared up to metamorphosis, but escaped before an identification could be made. Seventeen stages of this series only were cut.

Including duplicates, there are 292 slides in all. All stages were cut transversely, and critical stages were cut in the sagittal and coronal planes also. The material was fixed in Zenker and stained in Delafield's haematoxylin and counterstained in orange G. The younger stages were covered with a film of celloidin to prevent the loss of yolk-laden cells which are likely to become detached. The closeness of the series and their sequence are particularly important in the discussion of the problem involved in this paper. Where a series is taken from more than one cluster of eggs, care was used to insure that the series would be continuous by having the eggs taken from the two lots overlap in time. 


\section{THE ORIGIN OF THE NEURAL CREST}

There are in the vertebrates three modes in which the neural crest is related to the neural tube and overlying ectoderm. Harrison ('01) has described and compared two of these. In the first type, the neural-crest cells-selachians and other typesrepresent the dorsal portion of the lateral walls of the neural tube which is at first continuous with the ectoderm. The neural crest is incorporated in the neural tube, forming a wedgeshaped mass in its dorsal portion. This wedge-shaped mass later becomes detached from the tube and migrates laterally and ventrally. In the second mode the neural crest (teleosts) lies between the dorsal border of the neural tube and the ectoderm, not being included strictly in either, but forming later a cap over the dorsal border of the neural tube. In the third mode (Ameiurus and other types (Landacre, '10)) the neural crest or cells homologous to the neural-crest cells remain in the ectoderm lateral to the neural canal and are later detached from this position to form parts of cranial ganglia and other structures.

The three series of urodeles studied correspond closely in the behavior of the neural crest to the first type mentioned above and do not require an extended description. The neural crest is completely incorporated in the dorsal border of the neural tube, but can be distinguished from the tube, usually, by its looser structure. The following description is based on the behavior of the crest at the level of the VII ganglion.

When the medullary plate can be identified first, it is very broad and its lateral borders include the two portions of the neural crest. Just before the closure of the neural canal (fig. 1) the superficial layer of the ectoderm and much of what will become neural crest are invaginated and included within the limits of the neural groove. The superficial heavily pigmented layer of the ectoderm forms the inner lining of the greater portion of the neural groove. The looser texture and greater pigmentation of the dorsomesial portions of the walls of the neural groove indicate roughly the position of the neural-crest cells. 
In the closure of the neural groove (fig. 2) the superficial pigmented cells lining the dorsal two-thirds of the neural tube come into contact and obliterate that portion of the canal lined by flat cells. The line of juncture is indicated by the heavy pigmentation of the cells. The dorsomesial portion of the wall of the tube has a looser texture and less of a syncytial character than the lateral and ventral portions. The neural tube as a whole is well delimited from the ectoderm except at the dorsal border.

The outline of the neural tube (fig. 3) as distinct from the neural crest first becomes apparent when the cells of the tube assume a syncytial character with their nuclei arranged with their long axes toward the center of the neural canal. At the same time the neural crest while still forming a conspicuous wedge in the dorsal portion of the tube is evidently now largely outside the limits of the tube. The dorsal third of the tube becomes neural crest and presents the appearance of being erupted from the tube. The tube is horseshoe-shaped with the open dorsal portion filled with a wedge of neural-crest cells. The tube except at the ventral border is of uniform thickness.

The next step (fig. 4) involves the further exclusion of neuralcrest cells from the dorsal wall of the tube. In this process many of the loosely arranged, heavily pigmented cells are left for a time in the position of the original wedge. In fact, after the neural crest is well defined and has begun to migrate ventrally (fig. 5) a few cells of this type still form the roof plate of the neural canal. In this stage (fig. 5) the greater portion of the neural crest rests upon the dorsal portion of the neural tube, but there are two prominent lateral extensions lying between the dorsolateral border of the neural tube and the ectoderm. At a slightly later stage (fig. 6) the neural crest is represented almost exclusively by these lateral extensions. The large mass of cells previously lying over the tube is now represented by a few flat cells connecting the two lateral portions of the neural crest. These flat cells disappear later. In figure 6 the original wedge seems to be represented by a few irregularly arranged cells. 
Up to the last stage described there is practically no indication that cells are added to the crest, as defined, from the lateral ectoderm. The crest is continuous on its dorsal border with the inner layer of the ectoderm, and undoubtedly receives cells from this source (figs. 1, 2, 3, and 5), and in several series at the age of that from which figure 3 is taken and the crest is continuous ventrally with the inner layer (fig. 3 ). This continuity is usually absent at the level under consideration as the lateral portions of the crest become better defined (figs. 5 and 6 ) and also in the earlier stages (fig. 4).

These conditions as described at the level of the VII ganglion are duplicated at the levels of ganglia $V$, IX, and $X$. In the intervals between these ganglia the neural-crest cells are less numerous and the lateral extensions contain fewer cells and do not reach so far ventrally. At the stage from which figure 5 was taken (fig. 7), the neural crest is continuous throughout the whole region. In the stage from which figure 6 was taken (fig. 8) the crest is interrupted, except for a few scattered cells on the dorsal portion of the cord, between the V and VII ganglia and again between the VII and IX ganglia.

THE MIGRATION OF THE NEURAL CREST AND ITS RELATION TO THE MESODERM

The accuracy with which the migration of the neural crest can be followed depends upon histological differences between cells derived from the ectoderm as distinguished from those derived from the endoderm. These distinctions have been stated already in the introduction (p. 2). They will be assumed for the present and the migration of the crest will be described from the reconstructions given in figures 7 to 11 . The discussion of the basis of these distinctions together with the discussion of two other disputed points, namely, the question as to the contribution by the lateral ectoderm of cells to the mesenchyme and the question as to the fate of cells in the anterior head region, will be deferred to a later section.

As to the use of terms, Miss Platt rejected the term 'mesentoderm' presumably because the term implies a derm or germ layer 
derived from entoderm, and of course this is equivalent to mesoderm and therefore superfluous. There is in the head region, however, a good deal of loose tissue quite similar to mesenchyme found in the trunk and like that found in the trunk, derived from mesoderm, which is itself a derivative of endoderm. Now, since it is necessary, in describing the behavior of mesenchyme in the head, to distinguish between that derived from the neural crest, which retains most of its ectodermal characters, and that derived from mesoderm, which for a long time retains its endodermal characters, I have ventured to suggest the terms 'entodermal mesenchyme' and 'ectodermal mesenchyme' for mesenchyme in the head where the two types of cells can be distinguished. When head mesenchyme becomes homogeneous, that is when we can no longer distinguish two types of cells, it will be referred to as mesenchyme, with the implication, however, that it sometimes contains both ectodermal and entodermal cells. While both types of mesenchyme have passed through intermediate stages, the entoderm through a mesodermal stage and the ectoderm through a neural crest stage, each retains the character of its more remote rather than of its immediate ancestor. This seems to justify the terms ectodermal mesenchyme and entodermal mesenchyme rather than neural-crest mesenchyme and mesodermal mesenchyme. The term ectodermal mesenchyme is substituted for mesectoderm, which has become general in the literature. The tissue we are dealing with is not a derm or layer, but a true mesenchyme quite similar to mesenchyme in the trunk, but coming from ectoderm rather than from mesoderm as is in the trunk.

The use of the terms ectodermal mesenchyme and endodermal mesenchyme is further justified by the fact that in the head all branchial muscles come from the mesoderm, and show throughout their earlier stages definite somatic and splanchnic layers, indicating their relation to the lateral mesoderm of the body, while the mesenchyme of the head is more or less loose and of a syncytial character, like that derived in the body from the sclerotomes and the lateral and splanchnic mesoderm. As the mesoderm of the anterior trunk region grows forward into the 
head, it gives rise to a) eye muscles from its dorsal or somitic portion; $b$ ) branchial muscles from its ventral portion, and, c) mesenchyme which retains it endodermal characters. That portion of head mesoderm which gives rise to branchial muscles does not become loose or syncytial in character as does the mesenchyme, but retains its integrity to such an extent that two layers, somatic and splanchnic, can for a long time be identified.

The neural crest, on the other hand, gives rise to specific cerebral ganglia such as V, VII, IX, and X and then migrates ventrally into the ventral head region and into the branchial bars and differentiates into cartilages and loose mesenchyme. The neural-crest ectoderm furnishes three specific derivatives, $a$ ) ganglia, $b$ ) cartilages, $c$ ) mesenchyme. Since the two types of mesenchyme overlap and are histologically distinct for a long time and since the ventral portion of the neural crest passes from a mesenchymal stage to a cartilaginous stage, the terms entodermal mesenchyme and ectodermal mesenchyme seem not only to be justified, but to be absolutely necessary to accurate description.

We shall first follow the migration of the neural crest and mesoderm.

In the first stage plotted, which is $3 \mathrm{~mm}$. in length (fig. 7), the neural crest is continuous along its dorsal border throughout the whole head region, beginning anteriorly at the level of the middle of the eye horizontally and extending caudally into the spinal neural crest. It presents three conspicuous enlargements. The anterior enlargement extends caudally to the vertical level of the posterior border of the eye. The gasserian ganglion differentiates out of the posterior portion of this enlargement and can be identified at this stage by the slight condensation of the cells. This enlargement is a ventral extension of the neural crest, but owing to the flexure of the head it seems to extend caudally.

The second enlargement or ventral extension is at the level of the VII ganglion, the third at the level of the IX ganglion, and the fourth inconspicuous enlargement at the level of the 
anterior division of the $\mathrm{X}$ ganglion. Posterior to this level the neural crest gradually becomes narrower dorsoventrally and passes into the neural crest of the spinal cord. In referring to the V, VII, IX, and X ganglia it is to be understood that only the general cutaneous and general visceral portions of these ganglia are under consideration. These are homologous to spinal ganglia. The special somatic and special visceral ganglia are referable to other sourres.

The endodermal derivatives at this stage fall into two regions. First the posterior head region, which extends cephalad to the level of the anterior end of the alimentary canal and is characterized by the presence of somites and a two-layered lateral mesoderm. The somites are not well defined at this stage and the lateral mesoderm forms a broad sheet extending from a level slightly dorsal to the notochord to the ventral limit of the body, being absent only in the heart region and the region of the stomodaeum.

The second, or anterior head region, lies anterior to the level of the anterior end of the alimentary canal and forms a loose mesial or axial mass of entodermal mesenchyme and two lateral extensions. These lateral extensions contain cavities which in the urodeles do not form definite head cavities or somites, but their dorsal portions are undoubtedly homologous to the head somites of selachians. The dorsal border of this entodermal mesenchyme maintains the same relative level as the dorsal border of the somites. It reaches cephalad to the vertical level of the middle of the optic vesicle and ventrally it forms a prominent extension, which is separated from the anterior border of the lateral mesoderm by an area free from mesoderm cells. This. area corresponds roughly to the future position of the spiracular gill cleft. The ventral border of this extension reaches nearly to the ventral limit of the optic vesicle. The whole of this anterior head mesoderm consists of the large endoderm cells containing large yolk granules and except those regions giving rise to eye and branchial muscle has a loose arrangement presaging its modification into typical mesenchyme. The neural crest overlaps the cells derived from endoderm at two points only- 
in the region of the $\mathrm{V}$ ganglion and at the ventral border of the IX ganglion. In the overlapping areas mentioned the entodermal mesoderm lies mesial to the neural crest.

In the second stage plotted, $3 \mathrm{~mm}$. in length (fig. 8), but six hours older than the last, the neural crest in the region of the gasserian ganglion and anterior to this ganglion has migrated ventrally and caudally and now forms two prominent extensions, the one anterior to the eye and mesial to the olfactory capsule, the other posterior to the eye and extending slightly into the mandibular bar ventral to its ganglion-forming region. This anterior neural crest is now completely detached from the neural crest in the region of the VII ganglion, except for a few scattered cells on the dorsal portion of the neural tube.

The neural crest at the level of the VII ganglion has grown ventrally to the region of the dorsal border of the alimentary canal, doubling its length as compared with the last stage. The IX ganglion has also grown ventrally to the same extent and the $\mathrm{X}$ is now represented by a conspicuous ventrocaudal extension of the same general neural-crest mass from which the IX ganglion forms. The neural crest of VII, IX, and X have not, as yet, grown ventrally beyond their ganglion-forming regions. The neural crest in the region of VII is connected dorsally by a welldefined strand of neural crest cells with that of ganglia IX and X.

The lateral mesoderm lying posterior to the anterior end of the alimentary canal at this stage is interrupted by the outgrowth of the endoderm to form the spiracular and hyoid pharyngeal pouches. The interruption of the lateral mesoderm at the level of the spiracular cleft is not formed entirely by the pharyngeal pocket. Its ventral portion represents the remains of the prominent notch shown just caudal to the eye in figure 7 .

The head mesoderm lying anterior to the alimentary canal has extended in two directions, dorsally and anteriorly, until it has reached the dorsal wall of the brain at the vertical level of the anterior end of the optic vesicle. It has also extended ventrally and caudally posterior to the optic vesicle. The posterior boundary of this extension lies just ventral to the spiracular pharyngeal pocket. The ventral limit of this extension 
reaches almost to the ventral border of the optic vesicle. The region of the overlapping of neural crest and mesoderm is quite extensive, as indicated in figure 8 . In the region just posterior to the eye the mesoderm is not completely covered by neural crest. In the region of the VII, IX, and X ganglion the ventral half of each ganglion overlaps the lateral mesoderm and lies lateral to it.

In figure 9 from a stage $4 \mathrm{~mm}$. long and ten hours older than the stage from which figure 8 was taken, the neural crest has not altered its relation greatly except that posterior to the eye it has grown ventrally and caudally into the mandibular bar and now almost covers, on the lateral surface, the primordium of the mandibular muscles. This extension reaches almost to the ventral limit of the body and far beyond the ventral limit of the $\mathrm{V}$ ganglion. In the region of the VII and $\mathrm{X}$ ganglia, the ventral extensions of the crest have moved into the hyoid and second true branchial bars reaching, at least in the case of VII, to the middle of the body and well beyond the ganglion-forming region. The crest in the region of IX shows little change.

The lateral mesoderm in the pharyngeal region is now interrupted by three visceral pouches, but is otherwise unmodified so far as its extent is concerned. In the anterior head region the mesoderm has extended cephalad over the eye and ventrally at the same level so that now it lies between the dorsal border of the optic vesicle and the brain. The increase in the amount of overlap of neural crest is most marked in the regions of the VII and X ganglia.

Figure 10 is taken from stage 12 of series III and is $4 \frac{1}{2} \mathrm{~mm}$. long and approximately twelve hours older than the stage from which figure 9 was taken. In this stage there are two striking changes in the extent of the neural crest noticeable in the anterior head region. The first is progressive and carries the neural crest ventrally and slightly cephalad in the region of the olfactory and optic vesicles. The olfactory capsule is now completely separated from the brain wall by a sheet of ectodermal cells which, extending ventral and caudal from the olfactory capsule, reaches the ventral limit of the brain wall below the optic vesicle. 
Much of the optic vesicle, aside from the region of the optic stalk, is separated from the brain wall by this continuous sheet of ectodermal mesenchyme.

The second change in this region is regressive and is indicated by the absence of ectodermal mesenchyme in the region lying vertically over the olfactory capsule. The question as to whether this is due to a withdrawal by migration or to a disappearance of the cells will be taken up in the next section. Although the anterior limit of the ectodermal mesenchyme is hard to determine on account of the scattered neural-crest cells in this region, there is no doubt that the process of disappearance of neural crest at this point has taken place. It is much more marked in the next stage plotted (fig. 11). Posterior to the eye, the change in the extent of the ectodermal mesenchyme is slight as seen from the lateral surface. It is almost coextensive with the primordium of the mandibular muscle mass. It surrounds this mass completely, however, so that the endodermal derivative of the mandibular bar is inclosed by a sheet of ectodermal mesenchyme except at its extreme posterior tip.

In the posterior head region at the levels of the VII, IX, and $\mathrm{X}$ ganglia the most marked changes are the ventral growth of the neural crest into the hyoid and first two true branchial bars, with the accompanying process of surrounding the endodermal derivatives (branchial muscles) in these bars by ectodermal cells. This last process is, of course, not indicated on the plot. Posterior to the pharyngeal pouch of the second true gill in the region of $\mathrm{X}$ the neural crest has not only grown ventrally, but also caudally as a broad sheet which will be pierced by the third true branchial pouch, thus setting off the second branchial ganglion of $X$ from the first. In this process the mode of development is altered somewhat, since in the more anterior gill bars the neural crest grows ventrally into the bars after they are formed by the pharyngeal endodermic evagination, while here the migration of the neural crest ventrally precedes the formation of the pharyngeal evagination and must be displaced by it. As in the more anterior ganglia, the dorsal portion of the broad mass extending caudally from $\mathrm{X}$ forms ganglion, while 
the ventral portion takes part in the formation of the mesenchyme and cartilage of the gill bar.

In the last stage plotted (fig. 11) from stage 1 of series II, $6 \mathrm{~mm}$. long, and approximately twenty-four hours older than that from which figure 10 was taken, the ectodermal mesenchyme has reached, except in the posterior pharyngeal region, its final distribution. Its later history involves its differentiation as distinct from its migration.

In the anterior head region, including the mandibular bar, the changes in distribution are both progressive and regressive. The most marked increase in extent of ectodermal mesenchyme in this region is in the mandibular bar due apparently to the growth of the bar. There is also a slight increase in the extreme anterior end of the head or rather a residue in the form of spur of ectodermal mesenchyme extending dorsally from the position of the epiphysis. This spur lies morphologically on the dorsal wall of the midbrain. In the region of the olfactory capsule the ectodermal mesenchyme forms a continuous sheet between the forebrain and ectoderm. It also forms a continuous sheet between the anterior border of the optic vesicle and ectoderm with a second spur extending dorsally to the level of the profundus ganglion and a third extending ventrally under the olfactory and optic capsules which is continuous with the ectodermal mesenchyme of the mandibular bar. Except for the first two spurs mentioned, the ectodermal mesenchyme is now confined as a continuous sheet to the anterior and ventral head regions anterior to the level of the gasserian ganglion. This represents a rather marked decrease in the relative extent of the ectodermal mesenchyme in the dorsal portion of the anterior head region.

In the posterior head region there is in this stage a marked ventral extension of the crest at the levels of V, VII, IX, and X ganglia. The ectodermal mesenchyme at these levels has grown into the corresponding gill bars and now reaches to the level of the heart and ventral aorta, covering from the lateral view the whole of the entodermal derivatives of these bars. Except in the posterior bar, the ectodermal mesenchyme has further completely surrounded the endodermal derivatives. Posterior 
to the last pharyngeal pouch, the neural crest forms a broad sheet which will be perforated by the pharyngeal pocket of the third true gill. In this stage the neural-crest portion of the $\mathrm{X}$ ganglia possesses two ventral extensions or pharyngeal ganglia in addition to the third broad band lying behind the last pharyngeal pouch.

In the lateral mesoderm posterior to the anterior end of the alimentary canal there is no change except that it is perforated by an additional pharyngeal pouch. The withdrawal of the lateral mesoderm in the region of the last pharyngeal pouch is more extensive than the contact between the ectoderm and endoderm, due apparently to the fact that this pouch excludes both ectodermal mesenchyme and entodermal mesenchyme in reaching the ectoderm. Mesoderm is certainly absent over a much larger area after the contact is formed than is ectodermal mesenchyme. Anterior to the anterior end of the alimentary canal the entodermal mesenchyme occupies the whole head region except the area ventral to a line drawn from the region of the epiphysis to the base of the hypophysis. In this region at this stage the mesenchyme is derived from ectoderm. The area of overlap in the anterior head region is slight and can be best understood by reference to the reconstruction (fig. 11). In the posterior head region the ectodermal mesenchyme and mesoderm are coextensive except in the regions between the ganglia $\mathrm{V}, \mathrm{VII}, \mathrm{IX}$, and $\mathrm{X}$ and in the region posterior to the $\mathrm{X}$ ganglia.

The general result of the migration of the neural crest may be stated as follows: it furnishes first the general somatic and general visceral portions of the $\mathrm{V}$, VII, IX, and $\mathrm{X}$ ganglia. Whether it furnishes other portions of the V, VII, IX, and $X$ ganglia must be deferred to a later paper. It also migrates into and furnishes mesenchyme in the early stages in the mandibular, hyoid, and pharyngeal gill bars. The mesenchyme at first lies lateral to the endodermal derivative which is always more dense in the bars, but later comes to completely surround it. The neural crest also furnishes a complete sheet of mesenchyme in the extreme ventral head region. The crest disappears as a 
continuous sheet in the region of the midbrain except for the two dorsally directed spurs shown in figure 11 and between the $V$ and VII ganglia, and as a continuous sheet disappears in the region immediately dorsal to the hypophysis. The identification of the crest in these regions rests on certain histological characters of its cells, but to some extent on the continuity of the sheet of cells which everywhere grows continuously in a ventral direction morphologically. The continuity of this sheet of ectodermal mesenchyme derived from the neural crest needs to be emphasized, since it facilitates greatly the identification of the progressive changes in extent of the crest. At points where the neural crest is diminishing in extent the problem of describing its boundaries is much more difficult.

The behavior of the head mesoderm, in addition to the facts shown by the plots, consists in the formation of branchial muscles from the lateral mesoderm, which do not lose their entodermal characters, the formation of eye muscles from the dorsal or somatic region of head mesoderm, and the formation of mesenchyme, particularly in the anterior and dorsal head regions, which mingles with detached cells derived from the neural crest to form later homogeneous head mesenchyme.

\section{THE DERIVATIVES OF THE LATERAL ECTODERM}

Among authors who derive mesenchyme from ectoderm, one of the most debated points is concerned with the origin of mesenchyme from the lateral surface ectoderm of the head as compared with the origin from the neural crest. Miss Platt, in her earlier paper ('94), derived ectodermal mesenchyme entirely from lateral ectoderm, but in her later paper seems to include the neural crest also a source of this tissue. Kupffer ('95) also, in Petromyzon, derives branchial cartilages and mesenchyme from the lateral ectoderm, which he designates as branchodermis, and later as neurodermis. Lundborg ('99)' and Koltzoff ('02) both derive mesenchyme from lateral ectoderm. Dohrn ('02), however, working on Torpedo ocellata, and Brauer ('04), working on the Gymnophiona, can find no evidence that anything but 
neural crest is concerned in the formation of ectodermal mesenchyme and cartilages.

This problem must be settled finally, of course, by observation; but since my results agree with those of Dohrn and Brauer, and since I have examined carefully types in which some authors derive mesenchyme from lateral surface ectoderm, it is interesting to examine conditions in the lateral ectoderm, which might have led to a misinterpretation of the facts by earlier authors.

The lateral ectoderm is concerned in the formation of a number of structures which do not form mesenchyme and their number and significance are impressive. These structures, taken approximately in the order of their sequence in development, are as follows:

$a$. In the early stages of the formation of the neural plate a few scattered cells lie between the lateral border of the neural plate and the thin surface ectoderm, but they are few in number and show every appearance of detached neural-crest cells. In the later migration ventrally of the neural crest they are either lost or incorporated with the neural crest. They certainly furnish no evidence for a general contribution of cells to the mesenchyme from the lateral ectoderm.

$b$. The profundus ganglion arises from the lateral ectoderm anterior to the gasserian ganglion and is quite extensive both in its longitudinal and its vertical diameters and shows at times the appearance of an extensive delamination. A careful study of its development shows, however, that the delamination of the ectoderm at this point is concerned solely with the formation of the profundus ganglion and not with mesenchyme.

$c$. The lateral ectoderm next gives rise to the lateral-line ganglion of nerves VII, IX, and X in certain types, and especially in those types in which the homologue of the neural crest is not included in the neural canal (type III, p. 11). These forms present the appearance of contributing cells to the mesenchyme. Their true fate, however, can be determined to be the formation of lateral-line ganglia, if one has a complete series taken at close intervals. 
d. The lateral ectoderm also gives rise to the lateral-line primordia (placodes) which are distinct structures, although in some types closely related in time of appearance and sometimes even in position with other structures derived from the lateral ectoderm. If followed carefully, however, their identity can be established with certainty. Their thickenings or placodes are usually accompanied by detached cells and should not lead to confusion as to their fate.

e. Next the lateral ectoderm gives rise to the epibranchial placodes which furnish the special visceral or gustatory portions of the VII, IX, and X ganglia. Since these placodes become completely detached from the lateral ectoderm and added to the neural-crest portions of the VII, IX, and X ganglia and do not always have definite boundaries, they might be misinterpreted as contributions of the lateral ectoderm to mesenchyme in the branchial region. If these placodes are followed carefully they are found to have nothing to do with mesenchyme, but are ganglion-forming structures.

Aside from the oral region, which must be taken up more in detail, these five structures are all that might be mistaken for contributions to the mesenchyme. The point to be emphasized, aside from our own observation, is this: any claim that the lateral ectoderm contributes to the formation of mesenchyme that does not take into consideration and account for the structures mentioned above is open to serious criticism. We believe that the disagreement among authors as to the exact condition in the lateral ectoderm is due to failure to account for the structures enumerated above before assuming that cells delaminated from the lateral ectoderm went into the formation of mesenchyme.

With the facts mentioned above in mind, we have examined carefully our series and, aside from the oral region yet to be described, we can find no evidence for the contribution of lateral ectoderm cells to mesenchyme. In fact, the ectoderm at all points except those mentioned is intact and shows no indication of liberating cells, and we find ourselves in the closest accord with the statements of Dohrn ('02) and Brauer ('04), who can find no such contribution. 
THE ORAL ECTODERM

Lastly, the oral region in the urodeles presents a curious condition with reference to the positions of ectoderm and endoderm. None of the authors interested primarily in the origin of head mesenchyme has described this region carefully. This is all the more striking, since, on superficial examination, it would seem to furnish the best evidence for the derivation of mesenchyme from the lateral ectoderm. Johnston ('10), working on the fate of the oral entoderm in Amblystoma, gives an accurate description of the oral region. He does not, however, follow the fate of the mesenchyme. My results agree with his, except in one particular.

I find, in agreement with Johnston, that the anterior end of the archenteron is open at first well forward to the position of the future oral opening. This open oral and pharyngeal cavity next becomes closed and forms a solid, flat column of entoderm abutting cephalad against the oral ectoderm, which at this point consists of the usual two layers, a superficial epithelium and a deeper layer of nervous ectoderm. The next change consists in the formation of a collar of ectoderm around the solid column of oral entoderm. This collar grows caudally from the anterior oral region and mesially from the lateral oral region as far as the position of the vomerine teeth, which is approximately the posterior boundary of the solid column of the oral entoderm. This ectodermic collar is derived from lateral ectoderm as distinct from neural crest. During the formation of the ectodermal collar the nervous layer of the ectoderm disappears at the line of the future opening, but we are unable to verify Johnston's statement that the ectoderm disappears entirely, leaving the endodermal column exposed at the oral region. In our preparations the surface ectoderm is never absent at this point before its rupture to form the oral opening.

The next change consists in the formation of a definite oral cavity in the previously solid column of oral endoderm. It splits from behind forward, and after the endodermal column splits, the thin layer of superficial ectoderm ruptures, thus forming 
a true oral cavity lined entirely by entoderm, but possessing a collar of ectoderm, dorsal to its roof and ventral to its floor. This curious relation of the ectoderm to the entoderm is to be interpreted as a modification of the usual process of producing an oral cavity or stomodaeum by the invagination of ectoderm. In the urodele the solid column of oral endoderm which abuts against the ectoderm cephalad prevents the formation of the usual ectodermal invagination and we have the ingrowth of ectoderm to form a collar around a solid column of endoderm, which later splits to form an oral cavity lined by endoderm instead of by ectoderm as in other vertebrates. The ectoderm which in other vertebrates lines the oral cavity is in the urodeles, consequently, separated from the oral cavity by endoderm.

The ectodermal collar is the structure of greatest interest in the present discussion. The shape of the mouth in the urodeles is indicated during the solid stage of the oral endoderm by the great breadth of the endodermal column; consequently, the ectodermal collar is also broad and appears in transverse sections as broad plates of ectoderm lying dorsal and ventral to the endodermal column. These plates are curled at the lateral borders of the solid endodermal column, bending dorsolaterally and ventrolaterally around the lateral borders of the endodermal column and projecting slightly between what will be the roof and the floor of the oral cavity. These infolded edges cover the future lips of the oral cavity laterally with ectoderm. The ingrowth of the ectodermic collar begins first in the 6-mm. larvae dorsal to the solid endodermic oral collar and later the ventral portion of the collar is formed in the same manner. Preceding the formation of the ventral portion of the collar, there is mesenchyme between the ventral surface of the endodermal oral column and the ectoderm of the mandible, which is of ectodermal origin. This statement is made in spite of the fact that occasionally an endodermic cell is found here. Many of these can easily be shown to be walls of blood-vessels or isolated blood-cells which retain their endodermic characters, while others can be shown to be solid extensions of blood-vessels, and it is probable that all of them are concerned with blood-vessel 
or lymphatic-vessel formation. However, when the ectodermal collar forms, its distinctness from the mesenchyme is quite evident, since the mesenchyme is loose in structure, while the ectodermal collar is dense and continuous with the deeper layer of the surface ectoderm. As to the later differentiation of the ectodermic collar, we find ourselves in agreement with Johnston ('10), who states that it gives rise to the dental ridges and teeth, while the endodermal lining of the oral cavity gives rise to the taste buds and oral epithelium.

Concerning the fate of the remaining cells of the ectodermic collar, we cannot make such definite statements. Aside from the teeth, the ectoderm gives rise to the dense tissue in which the teeth are imbedded. The dental ridges and teeth, however, disarrange the cells of the ectodermic collar where it comes into contact with mesenchyme, and the collar may possibly contribute to the mesenchyme, but the indications are against such an interpretation. We have followed the ectodermic collar up to the time when membrane bone begins to form around Meckel's cartilage and about the bases of the teeth. At this late stage one is forced to the uncertain method of tracing derivation by position mainly. Based on this criterion, the bone that forms about Meckel's cartilage comes from the mesenchyme of both ectodermal and endodermal origin, while the membrane surrounding the teeth seems to come from ectoderm only. It is certainly formed in the same dense tissue of the collar from which the teeth arise, although we cannot exclude the possibility of the migration of mesenchyme cells of mixed origin into the ectodermal collar. The late stage at which true membrane bone forms renders it unsafe to make definite statements concerning its derivation from ectodermal mesenchyme as distinct from entodermal mesenchyme because of the fact that both types are similar in structure, owing to the loss of yolk granules by the endoderm and the reduction in size of entodermal mesenchyme cells.

My conclusion, therefore, concerning the contribution of the lateral ectoderm to mesenchyme is that the lateral ectoderm, aside from the oral ectodermic collar and its derivations, is not 
concerned in the formation of mesenchyme and that any delamination of cells from the lateral ectoderm is readily explained as concerned in the formation of other well-known structures. Dorsal and ventral to the oral cavity ectoderm forms the dense connective tissue in which the teeth are imbedded, but I find no evidence for the derivation of loose mesenchyme from the lateral ingrowth of ectoderm.

\section{THE DIFFERENTIATION OF THE MESODERM AND NEURAL CREST IN THE HEAD}

The possibility of following the differentiation of mesoderm into muscles, cartilages, and entodermal mesenchyme, and of neural crest into ganglia, ectodermal mesenchyme, and cartilages depends, as indicated earlier in this paper, upon easily recognized histological differences in ectodermal and entodermal cells. Ectodermal cells are smaller than entodermal cells, are usually pigmented, containing brown pigmented granules, and usually contain few yolk granules, or, if loaded with yolk granules, the granules are small and fairly uniform in size. Entodermal cells, on the other hand, are large and contain large numbers of large granules of varying sizes, and are not pigmented. When an embryo is stained with Delafield's haematoxylin and orange G, the contrast between neural crest and mesoderm is very striking.

These differences between ectodermal and entodermal derivatives can be followed in the urodeles up to the stage where the neural-crest ganglia, branchial muscles and eye muscles, branchial and cranial cartilages can be readily identified. One can follow the differentiation of the ectoderm and entoderm into mesenchyme with ease where the two types do not overlap. In areas of overlap even, the two types can be followed easily in the earlier stages when they lie in continuous sheets of cells. In the loose mesenchyme where the ectodermal and endodermal mesenchyme cells are mingled one can for a long time identify with certainty ectodermal and endodermal mesenchyme cells. The loose mesenchyme finally becomes homogeneous, entodermal cells assuming the appearance of ectodermal cells, and after this stage it is impossible to say which type of cell predominates. 
It is a rather striking fact in the distribution of ectoderm and endoderm in the head that, in general, ectoderm gives rise to mesenchyme and cartilages located ventrally, that is, farthest from its source of origin, while mosoderm gives rise to mesenchyme in the dorsal regions of the head, which makes its location farthest from its source of origin. The loose entodermal mesenchyme of the head is derived in part from the mesoderm, which also gives rise to branchial muscles ventrally and to eye muscles dorsally. The actual formation of mesenchyme in these locations consists in the detachment of individual cells from the mesial surface of the more anterior and ventral muscle primordia, such as the masseter and temporalis, as well as from the more dorsal mesoderm from which eye muscles arise.

That portion of mesoderm which migrates beyond the muscleforming area breaks down completely into loose mesenchyme. The mesoderm of the head, therefore, shows two types of tissue, a) dense masses of cells which can be followed into definitive branchial and eye muscles, retaining all the time their entodermal character up to the time muscle fibrils appear in the case of branchial muscles, and, $b$ ) loose mesenchyme which gradually loses its entodermal character and assumes the form of ectodermal mesenchyme.

The formation of ectodermal mesenchyme and cartilages from neural crest is really easier to follow than the mesodermal derivatives, except in the dorsal head regions from which the ectodermal mesenchyme withdraws as a continuous sheet. The neural crest, in its ventral migration, forms a continuous sheet of cells readily distinguished from mesoderm and lying lateral to the mesoderm. This continuous sheet of neural-crest cells gives rise, in its dorsal region, to the neural-crest ganglia and in other dorsal regions disintegrates into mesenchyme, which disappears as a continuous sheet in certain regions as indicated in figures 9,10 and 11 .

That portion of the neural crest which migrates into the ventral head region, that is, dorsal and ventral to the oral region and into the branchial bars, presents a quite different history. This ventral portion of the neural crest does not disintegrate. It not 
,nly maintains its continuity, but grows extensively, surrounding whe branchial muscles and filling the areas between muscles and epithelial structures. In this rather dense and continuous sheet of neural-crest cells there can be identified the still more condensed areas where the cartilages, such as Meckel's and the branchial cartilages, will form. Coincident with the formation of procartilage, there is going on a disintegration of the remaining neural crest to form loose ectodermal mesenchyme in much the same way as loose entodermal mesenchyme is formed from the mesoderm in more dorsal regions. Consequently, in the ventral head and branchial regions where the mesoderm gives rise to the muscles, most of the loose mesenchyme is derived from neural crest and is therefore ectodermal, while in the dorsal head regions, from which neural crest has disappeared as a continuous sheet, it is chiefly entodermal (mesodermal) mesenchyme.

Our conclusions concerning the metamorphosis of neural-crest cells into cartilage (excepting Miss Platt's conception of the behavior of lateral ectoderm) are so closely in accord with those of Platt, Dohrn, and Brauer that it is not necessary to give a detailed . ussion of the process. The branchial cartilages all differentiate out of the ventralmost extension of the neural crest. They all show uniformly a stage where the neural crest is in the form of a sheet of cells surrounding the corresponding mesodermic branchial muscle primordium. Since this sheet of neural-crest cells forms a syncytium, it is true mesenchyme, although somewhat more compact than entodermal mesenchyme. Throughout the whole ventral head region and branchial region the differentiation of this primitive mesenchyme shows two types of behavior: a) Where no cartilages form its cells become detached from the sheet of neural-crest cells and form loose mesenchyme surrounding muscles and cartilages. This is practically pure ectodermal mesenchyme. The few entodermal cells found may prove usually to be growing blood-vessels or bloodcells; $b$ ) where a cartilage forms the neural-crest cells first increase in number, then condense, passing through typical procartilage stages, and finally form true cartilage. We find, in agreement with Miss Platt, that the anterior portion of the trabecular 
bars, the palatoquadrate and Meckel's cartilages, all the brancnı1 cartilages except the second basibranchial are formed from ectodermal mesenehyme, while the posterior portion of the trabecular bars, the parachordals and basal plate of the chondrocranium along with the occipital arch arise from entodermal mesenchyme. The roof of the chondrocranium arises very late and is assumed to come from entodermal mesenchyme on the basis of the distribution as shown in figure 11, although at the stage when the lateral walls of the cranium appear the mesenchyme is homogeneous. I am unable to determine the composition of the brain membranes and their homologues, the choroid and sclerotic coats of the eye, on account of the lateness of their formation, which occurs after the mesenchyme from which they form has become homogeneous. The cartilages listed above as ectodermic or entodermic in origin show, in addition to the fact that their development from ectoderm and entoderm can be followed, quite definite ectodermic and entodermic characters after they have assumed their definitive forms and after their cells are surrounded by hyaline material so dense that cell division within the cartilage has practically ceased.

The formation of the second basibranchial from entoderm needs a word of explanation. The second basibranchial of Miss Platt is the urohyal of some authors. It is the most caudal of the median branchial cartilages and lies ventral to the other branchial cartilages, except at its anterior attached extremity. It develops from mesoderm along with the paired geniohyoid muscles which are attached to its extremity. The mesoderm from which these three structures develop is continuous at first with the lateral borders of the alimentary canal from which other muscle primordia form. It retains for a long time its entodermal type of cell, so that there can be no question as to its origin. No explanation is offered of this curious fact further than that suggested by its position, which, as shown by a reference to figure 11 , is at a point where ectoderm does not extend, that is, on the midventral line ventral to third, fourth, and fifth branchial bars. 
The same explanation is offered for the double composition of the trabeculae. The anterior portions of the trabeculae form in a region dominated by ectodermal mesenchyme. This region lies between the two dorsal spurs just over the eye in figure 11, while the caudal portions of the trabeculae and the parachordals form in a region containing axial entodermal mesenchyme.

\section{SUMMARY}

1. The neural crest in the urodeles is incorporated in the neural canal at first and later erupted and then grows ventrally as a continuous sheet of cells. This ventral migration carries it into the ventral region of the anterior portion of the head and into the ventral portions of the mandibular and branchial bars.

2. The dorsal portion of the neural-crest sheet gives rise to the general cutaneous and general visceral portions of ganglia $\mathrm{V}$, VII, IX, and X cranial nerves. The dorsal portion of the neural crest not concerned in the formation of ganglia disintegrates to form mesenchyme, which becomes mingled with entodermal mesenchyme in the dorsal head region.

3 . The ventral portion of the continuous neural-crest sheet, after migrating into the ventral head region and into the mandibular and branchial bars, surrounds the primordia of branchial muscles growing from their lateral surfaces around to their mesial surfaces. This ventral portion of the neural crest later differentiates into loose ectodermal mesenchyme and into dense cartilage primordia, which pass through procartilage into typical cartilages.

4. The greater portion of the mesenchyme in the ventral head region and in the branchial regions is consequently ectodermal mesenchyme.

5. The cartilages arising from ectoderm are the anterior portion of the trabeculae, Meckel's cartilage, the palatoquadrate bar, and all the branchial cartilages except the second basibranchial or urohyal.

6. The mesoderm in the head gives rise to the branchial muscles, to the eye muscles, and to loose entodermal mesen- 
chyme, which retains for a long time its entodermal characteristics. Entodermal mesenchyme later differentiates into cartilages forming the posterior portion of the trabeculae, the parachordals and base of the cranium, the occipital arch, the auditory capsule, and probably the lateral walls of the cranium.

7. The neural crest and mesoderm, where not concerned in the formation of ganglia and muscles, respectively, shift their positions extensively, but the net result of their migrations is to leave entodermal mesenchyme in the dorsal head regions, ectodermal mesenchyme in the ventral head regions, and mixed mesenchyme in the median longitudinal axis of the head. Where this overlapping occurs ectodermal mesenchyme is lateral in position, while entodermal mesenchyme is mesial in position. The loose axial mesenchyme lying in the median line between the brain floor and the dorsal surface of the mouth and pharynx is almost pure entodermal mesenchyme.

8. The lateral ectoderm, aside from the oral region, is not concerned in the formation of mesenchyme, but does give rise to the profundus ganglion, to lateral-line ganglia, to lateralline organs, and to epibranchial ganglia.

9. The lateral ectoderm in the oral region gives rise to an ectodermic collar, which surrounds the solid entoderm of the oral region, and in this collar arise dental ridges and teeth and dense connective tissue in which the teeth are imbedded. We can find no evidence for the formation of loose mesenchyme from this ectodermic collar.

10. The histological grounds on which the distinctions in the behavior of ectoderm and entoderm rest are as follows: entoderm cells are larger than ectoderm cells: entoderm cells are rarely pigmented, while ectoderm cells usually are. Ectoderm contains small, fairly uniform-size yolk granules and loses them early, while entoderm contains, large granules of irregular size and retains them much longer. In addition to these histological differences, the continuity of sheets of ectoderm and of entoderm cells is a valuable aid in following their distribution. The distinctions mentioned above can be observed after definitive ganglia, muscles, cartilages, and mesenchyme are formed. 


\section{LITERATURE CITED}

Brader, August 1904 Beiträge zur Kenntnis der Entwickelung und Anatomie der Gymnophionen. IV. Die Entwickelung der beiden trigeminus ganglion. Zoolog. Jahr., Suppl. Bd. 7.

Buchs, Grorg 1902 Über den Ursprung des Kopfskelets bei Necturus. Morphol. Jahrb., Bd. 39, H. 4.

Corning, H. K. 1899 Über einige Entwicklungsvorgänge am Kopfe der Anuren. Morph. Jahrb., Bd. 27.

Doнre, A. 1902 Studien zur Urgeschichte des Wirbeltierkörpers. XXII. Weitere Beiträge zur Beurteilung der Occipitalregion und der Ganglionleiste der Selachier. Mitteil. aus der Zoolog. Station zu Neapel, Bd. 15, H. 4.

Goronowitsch, N. 1892 Die axiale und die laterale Kopfmetamere der Vogelembryonen. Die Rolle der sog. 'Ganglionleisten' im Aufbaue der Nervenstamme. Anatomischer Anzeiger, Bd. 7.

1893 a Untersuchungen über die Entwickelung der sog. 'Ganglionleisten' im Kopfe der Vogelembryonen. Morph. Jahr., Bd. 20.

1893 b Weiteres iuber die ectodermale Entstehung von Skeletananlagen im Kopfe der Wirbelthiere. Morph. Jahrb., Bd. 20.

HARRISON, R. G. 1895 Die Entwickelung der unpaaren und paarigen Flossen der Teleostier. Arch. f. Mikr. Anat., Bd. 46.

1901 Ueber die Histogenese des peripheren Nervensystems der Salmo salar. Arch. f. Mikr. Anat., Bd. 57.

Johnston, J. B. 1910 The limit between ectoderm and entoderm in the mouth and the origin of the taste buds. Am. Jour. Anat., vol. 10, no. 1.

Kastschenke, N. 1888 Zur Entwickelungsgeschichte des Selachier Embryos. Anat. Anz., Bd. 3, No. 16.

KlaAtch, H. 1894 Ueber die Herkunft der Scleroblasten. Morph. Jahrb., Bd. 21, H. 2.

KUPFFER, C. v. 1894 Studien zur vergleichenden Entwickelungsgeschichte des Kopfes von Ammocoetes planeri. München und Leipzig, 1894.

1895 Über die Entwickelung des Kiemenskelets von Ammocoetes und die organogene Bestimmung des Exoderms. Verh. d. Anat. Ges. a. d. g. Vers. in Basl. Ergänzungsheft 2. Bd. 10, d. Anat. Anz. Bd. 3, s. 589.

Koutzoff, N. K. 1902 Entwickelungsgeschichte des Kopfes von Petromyzon planeri. Bull. Soc. Natural Moscou, vol. 15.

Lundborg, H. von 1899 Studien über die Betheiligung des Ektoderms an der Bildung des Menenchyms bei den niederen Vertebraten. Morph. Jahrb., Bd. 27, H. 2.

LANDACRE, F. L. 1910 The origin of the cranial ganglia in Ameiurus. Jour. Comp. Neur., vol. 20, no. 4.

Marshall, A. M. 1878 The cranial nerves in the chick. Quar. Jour. Micros. Sci., vol. 18.

Mrnot, C. S. 1901 The embryological basis of pathology. Science, vol. 13.

Neat, H. V. 1898 The segmentation of the nervous system in Squalus acanthias. A contribution to the morphology of the vertebrate head. Bull. Museum of Comp. Zool. at Harvard, vol. 31. 
Platt, Julia B. 1893 Ectodermic origin of the cartilages of the head. Anat Anz., Bd. 8.

1894 Ontogenetische Differenzierung des Ektodermis in Necturus Arch. Mikros. Anat., Bd. 45.

1896 Ontogenetic differentiations of the ectoderm in Necturus, St. II. Quar. Jour. Micros. Sci., N. S., vol. 39.

1897 The development of the cartilaginous skull and of the branchial and hypoglossal musculature in Necturus. Morph. Jahrb., Bd. 25, H. 3.

RABL, C. 1894 Ueber die Herkunft des Skelets. Verh. Anat. Ges., 8. Vers.

WiJhe, J. W. vaN 1882 Ueber die Mesodermsegments und die Entwicklung der Nerven des Selachierkopfes. Verh. d. Konikl. Akademie (Amsterdam) 


\section{PLATE 1}

\section{EXPLANATION OF FIGURES}

Figures 1, 2, 3, 4, 5 and 6 are transverse sections of Plethodon glutinosus at the level of the VII ganglion. The figures were drawn at a mangification of 275 and reduced one-half in reproduction. Figures 1, 2, 3, 4 and 5 are from larvae between 2 and $3 \mathrm{~mm}$. in length. Figure 6 is from larvae $3 \mathrm{~mm}$. in length.

1 Open neural canal stage.

2 Closed neural canal stage with the neural crest included in the neural tube.

3 Shows the 'eruption' of the neural crest. The neural crest forms part of the neural tube, but is easily distinguished from the tube.

4 The neural crest is largely outside the neural tube, but still forms a plug in its dorsal border.

5 Shows the neural crest almost completely outside the neural tube.

6 Shows the neural crest present in the form of typical cerebral ganglia. 

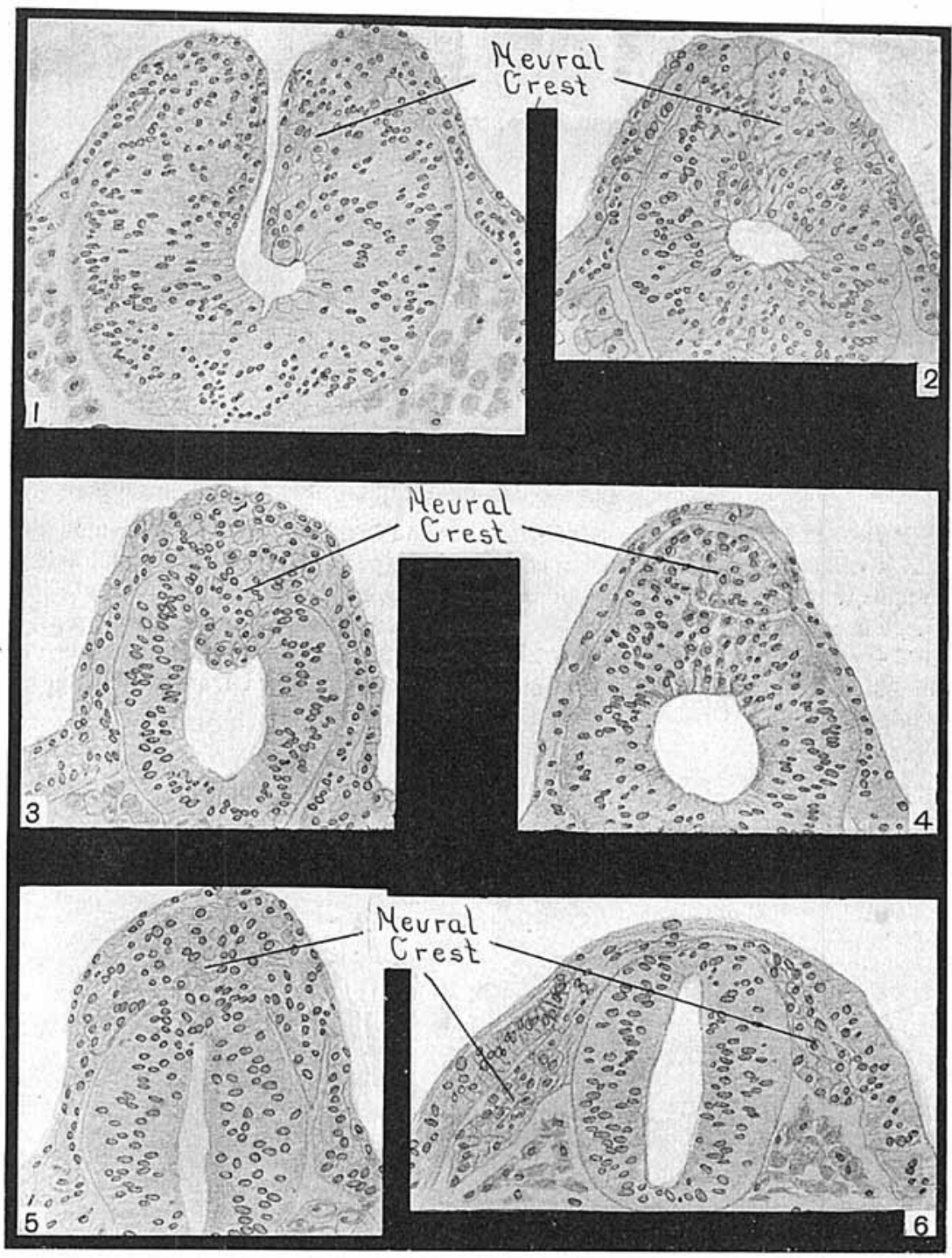


\section{PLATE 2}

\section{EXPLANATION OF FIGURES}

Figures 7 and 8 are flat reconstructions of the neural crest and mesoderm made by projecting the camera figures on coordinate paper. The plates give an accurate picture of the extent of the neural crest (diagonal lines) and mesoderm (stipple). The neural canal, notochord, alimentary canal, and sense organs are represented by lines. Both figures are from larvae $3 \mathrm{~mm}$. in length, but the larva from which figure 8 is taken is six hours older than the larva from which figure 7 is taken. 

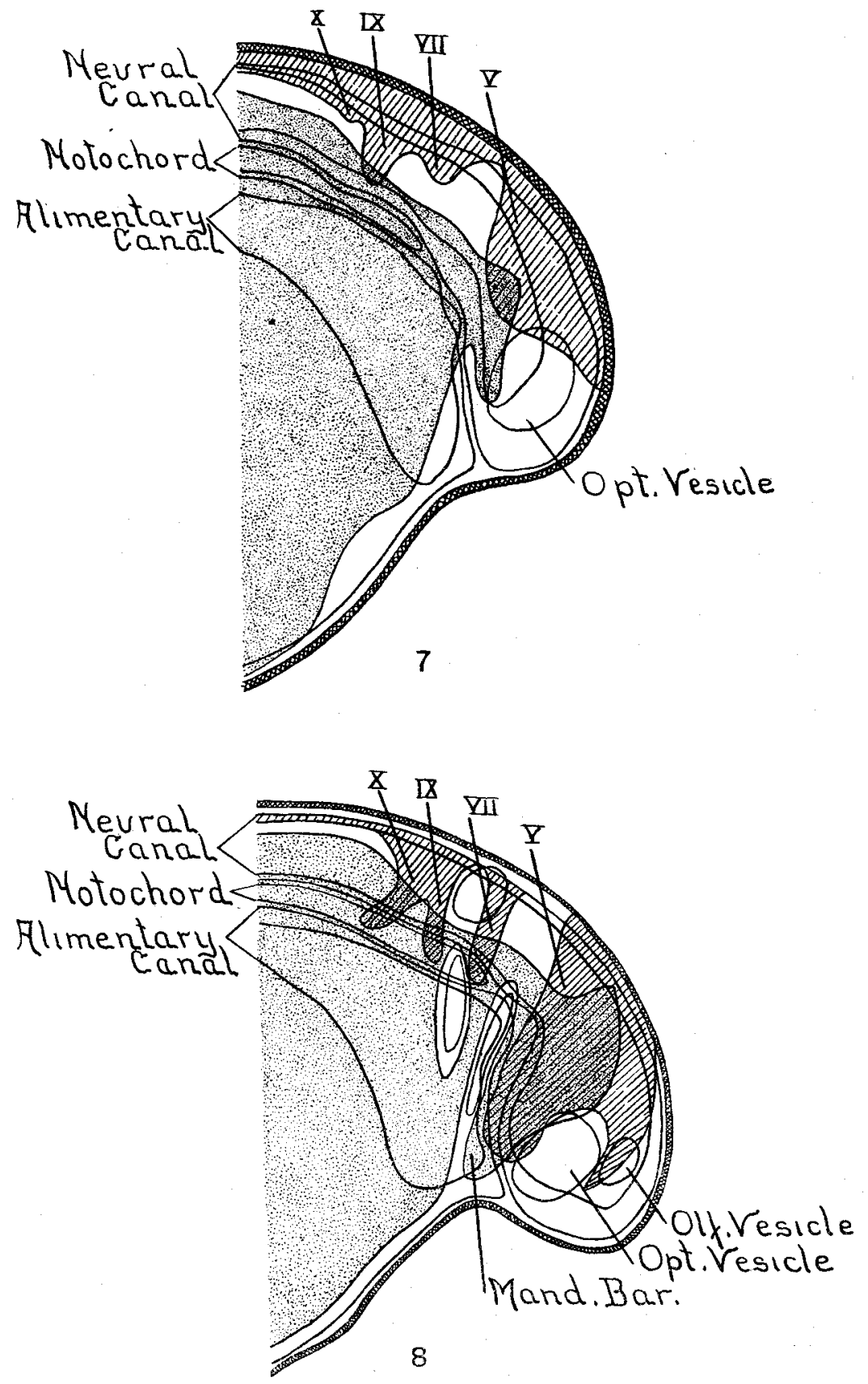
PLATE 3

EXPLANATION OF FIGURES

Figures 9 and 10 are reconstructions similar to figures 7 and 8 . Figure 9 is from a larva $4 \mathrm{~mm}$. long and figure 10 from a larva $4 \frac{1}{2} \mathrm{~mm}$. long. The neural crest is in diagonal lines and mesoderm in stipple. 

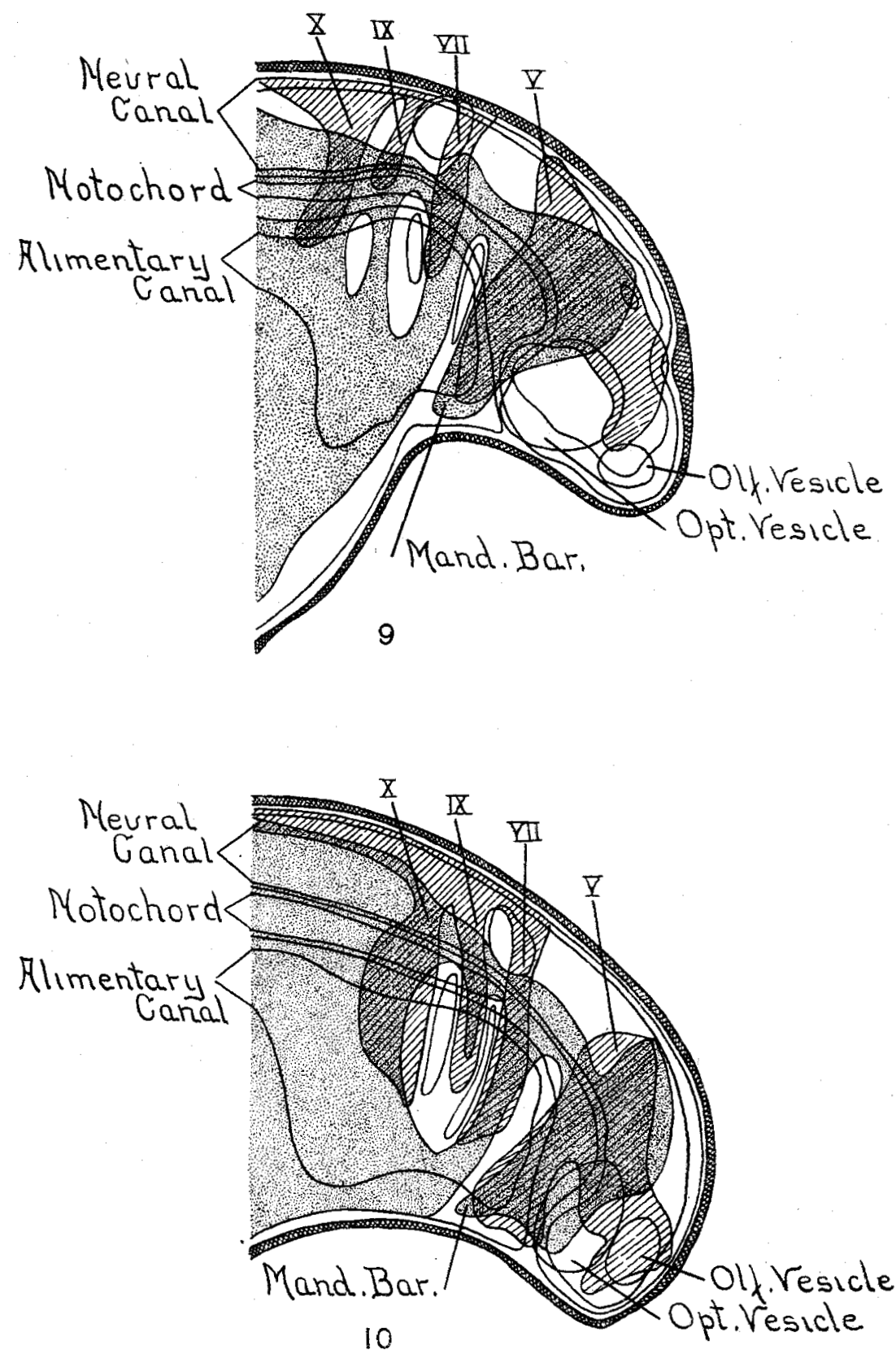
PLATE 4

EXPLANATION OF FIGURE

Figure 11 is a reconstruction similar to figures $7,8,9$, and 10. This larva was $6 \mathrm{~mm}$. long. Cerebral ganglia are represented by cross-hatched lines; neural crest by diagonal lines, and mesoderm by stipple. The neural canal, notochord, alimentary canal, and sense organs are represented by lines. The gill slits are unshaded. All of the neural erest below the ventral border of the cerebral ganglia will be converted into mesenchyme or cartilages. 


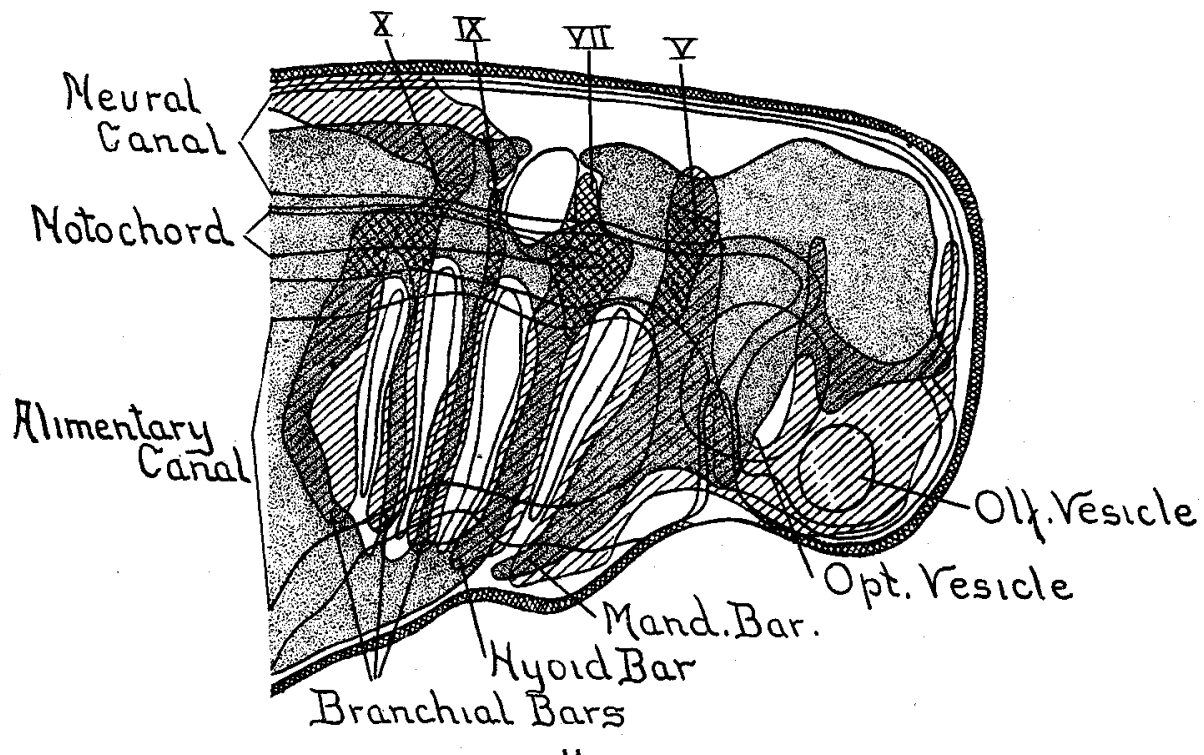

